\title{
Clostridium paraputrificum as rare causative of life- threatening spontaneous necrotizing cellulitis of the abdominal wall
}

Joerg Lindenmann ${ }^{1 *}$, Nicole Fink-Neuboeck' ${ }^{1}$ Eva Leitner ${ }^{2}$, Andrea Grisold ${ }^{2}$, Peter Kohek ${ }^{3}$ and Freyja Maria Smolle-Juettner ${ }^{1}$

*Corresponding author: jo.lindenmann@medunigraz.at

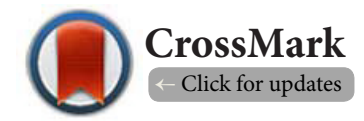

'Division of Thoracic and Hyperbaric Surgery, Medical University Graz, Austria.

${ }^{2}$ Instituteof Hygiene, Microbiology and Environmental Medicine, Medical University of Graz, Austria.

${ }^{3}$ Department of Surgery, Medical University Graz, Austria.

\begin{abstract}
Background: Necrotizing soft-tissue infections, in particular clostridial myonecrosis (gas gangrene), represent acuteand potential life-threatening emergencies still associated with high mortality.

Objective: This report emphasizes that in case of gas gangrene very early identification followed by immediate aggressive interdisciplinary treatment are of utmost importance for survival.

Case presentation: A 70-year-old female was admitted with a giant umbilical hernia suffering from abdominal gas gangrene combined with severe septic shock. After emergency laparotomy, enhanced intravenous broad-spectrum-antibiotics and consistent hyperbaric oxygenation (HBO), the patient's general condition improved considerably. During the further course she fully recovered and was discharged on the $14^{\text {th }}$ postoperative day.

Conclusion: This case is the first report of life-threatening abdominal gas gangrene induced by Clostridium paraputrificum treated successfully with emergency surgery, antibiotics and supportive $\mathrm{HBO}$, respectively. By means of this promptly initiated multimodal emergency treatment the patient's life could be saved last-minute.
\end{abstract}

Keywords: Gas gangrene, necrotizing soft-tissue infection, emergency, mortality, septic shock, antibiotics, surgery, hyperbaric oxygenation

\section{Introduction}

Gas gangrene represents a severe necrotizing and rapidly progressive soft-tissue infection. Clostridium (C.), an anaerobic gram-positive bacterium is known as the main causative agent for this acute life-threatening disease. In particular the C. species perfringens, septicum and histolyticum are the principal causes forth is type of necrotizing infection [1-3]. Basically, gas gangrene frequently develops in these areas of the body that have been compromised or injured by for eignbody, trauma, ischemia, malignancy or surgery [2]. In the vast majority of the cases the extremities are affected [3].

Other reported risk factors include age greaterthan 50 years, peripheral vascular disease, diabetes mellitus, malnutrition, atherosclerosis, obesity, hypoalbuminemia, chronic alcoholism, intravenous drug abuse, corticosteroid therapy and postoperative infection, respectively. However, many of these reported risk factors seem to reflect an immunosuppressed condition of the affected patient $[2,3]$.

After the rapid development of extensive hemorrhagic, blistering soft-tissue necrosis [2] the patient's general condition deteriorates continuously. $C$. are able to produce potent exotoxins which trigger multisystem organ failure culminating in severe septic shock $[1,3]$. Due to this rapidly deteriorating course, mortality rates are still high ranging up to $80 \%$ [3].

The adequate emergency management is based on prompt surgical debridement and immediate initiation of empiric intravenous antimicrobial therapy. Penicillin $G$ still remains the corner stone in the combined antibiotic therapy of gas gangrene $[2, \mathbf{3}]$ Besides surgery and antimicrobial therapy, hyperbaric oxygenation $(\mathrm{HBO})$ has turned out as an effective adjunct therapeutic 
tool within the past 20 years. Although some authors seem not to be fully persuaded of the clinical benefit of $\operatorname{HBO}[2, \mathbf{3}]$, $\mathrm{HBO}$ has proven to serve as a life-saving and therefore valuable supportive treatment option within this combined multimodal therapeutic approach [4-7].

We report the case of a female patient suffering from extensive abdominal gas gangrene induced by the rare $C$. paraputrificum treated last-minute with emergency treatment consisting of surgery, antibiotics and supportive HBO.

\section{Case presentation}

A 70-year-old female was admitted to the emergency department with increasing abdominal pain that had started only a few hours before. She showed signs of severe septic shock, her general condition decreased progressively. Physical examination revealed a dark blue-reddish discoloration and blistering of the skin over a large, chronic umbilical hernia (Figure 1A). A discreet livid discoloration with irregular borders spread from the maximum point of the local findings to the surrounding abdominal wall (Figure 1B). Changesat the skin had developed rapidly within the last four hours.

At admission, body temperature was $36.8^{\circ} \mathrm{C}$, blood pressure was $95 / 40 \mathrm{mmHg}$, and pulse was $135 \mathrm{bpm}$. Laboratory findings showed leucocytosis (17.6 G/l), C-reactive protein $330 \mathrm{mg} / \mathrm{L}$ (reference level $>5 \mathrm{mg} / \mathrm{L}$ ), procalcitonin $3.89 \mathrm{ng} / \mathrm{ml}$ (reference level $>0.5 \mathrm{ng} / \mathrm{ml}$ ), creatinine $2.44 \mathrm{mg} / \mathrm{dl}$, lactate $11.0 \mathrm{mmol} / \mathrm{l}$, and myoglobin $371.3 \mathrm{ng} / \mathrm{ml}$. The patient had recently undergone the fourth cycle of neo-adjuvant chemotherapy for breast cancer. At the oncological control one week before admission she had neither shown evidence of leucocytopenia nor of infection.

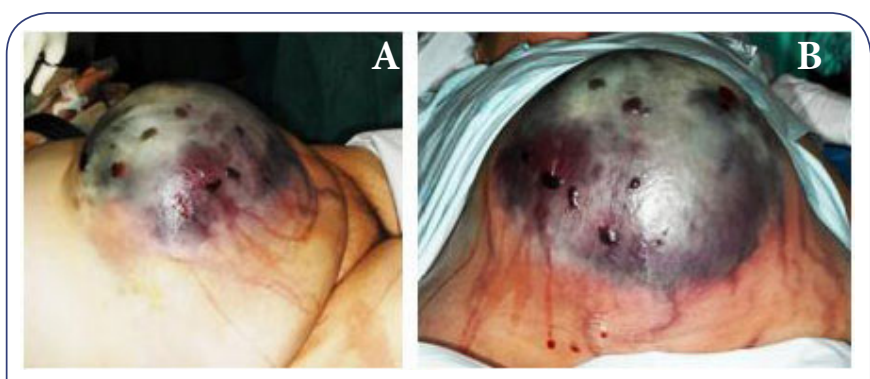

Figure 1. Clinical appearance of the patient on admission. Note the dark blue-reddish discoloration and blistering of the skin over a large, chronic umbilical hernia (A: View from the right hand side, B: View from the bottom up).

Further underlying conditions were diabetes mellitus, arterial hypertension, and coronary heart disease. Unfortunately, she was allergic to penicillin.

A swab from the fetid smelling contents of a blister was taken, an urgent Gram-staining clearly revealed Gram-positive rods with terminal spores (Figure 2). Asvab from the fetid smelling contents of a blister was taken, anurgent Gram-staining clearly revealed Gram-positive rods. Necrotizing infection due to Clostridia, a potential life-threatening anaerobic microorganism, was therefore suspected and enhanced intravenous antibiotic treatment with meropenem and metronidazol was initiated promptly.

Emergency laparotomy revealed incarceration and hemorrhagic infarction of about one meter of jejunum which had to be resected. During meticulous intra-abdominal exploration no perforation of the gut was found. Skin and subcutis covering the hernia were completely necrotic and foul-smelling, there was no pus (Figure 3).

The muscles of the surrounding abdominal wall were almost intact. After generously resection of the affected fatty tissue and debridement of necroses the abdomen was preliminarily closed. During emergency surgery the patient had to be resuscitated twice due to asystoly, high doses of catecholamines and volume substitution were required to maintain circulation.

Two hours postoperatively, after stabilization of the patient's hemodynamic condition, the patient underwent the first treatment session according to Boerema's schedule for gas gangrene

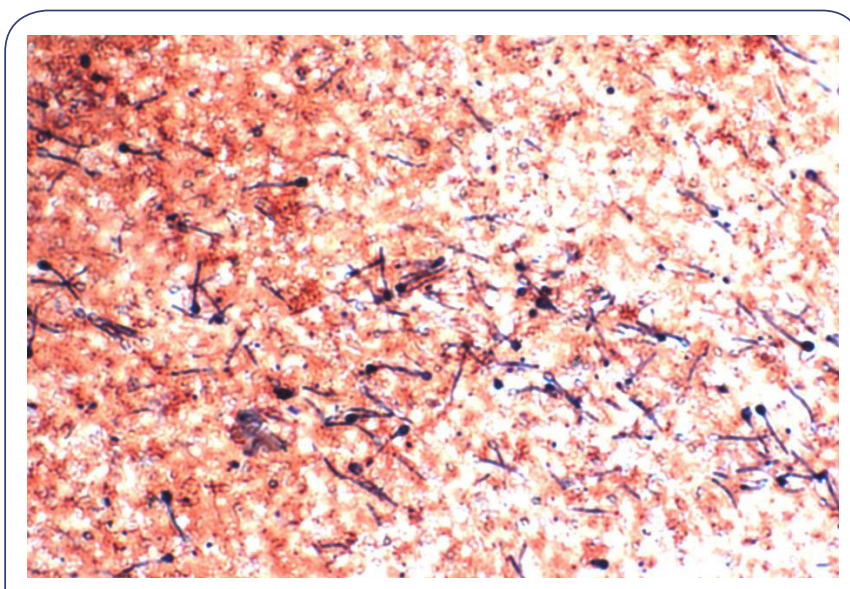

Figure 2. Gram stain of C. paraputrificum showing Gram-positive rods with terminal spores.

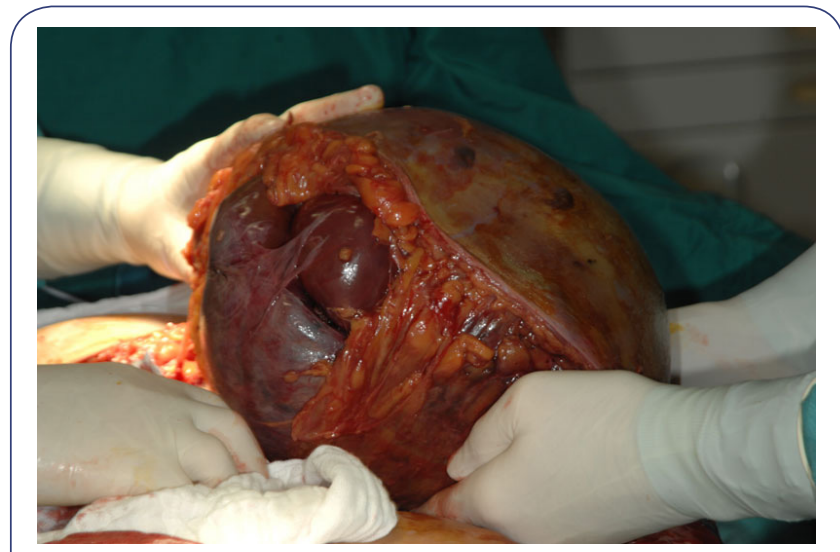

Figure 3. Surgical resection of the necrotic abdominal wall combined with partial resection of the incarcerated small intestine which is clearly visible by the livid color. 
in the hyperbaric chamber (Figure 4) [4]. Further nine sessions of HBO for the following seven days were scheduled.

On the next day the very rare C. paraputrificum was definitely identified in the culture from the swab. No other microorganisms could be isolated from the soft-tissue covering the hernia. Colonies of C. paraputrificum were found on Schädler agar (bioMérieux, Marcy l'Etoile, France) after anaerobic incubation for $24-48 \mathrm{hr}$ at $35^{\circ} \mathrm{C}$ (Figure 5). Identification was performed using the Vitek MS (bioMérieux). Resistance testing of $C$. paraputrificum was performed according EUCAST guidelines (http://www.eucast.org) revealing susceptibility to penicillin $(0.25 \mathrm{mg} / \mathrm{L})$, amoxycillin $(0.125 \mathrm{mg} / \mathrm{L})$, piperacillin/tazobactam $(0.25 \mathrm{mg} / \mathrm{L})$, meropenem $(0.25 \mathrm{mg} / \mathrm{L})$, metronidazole $(0.125$ $\mathrm{mg} / \mathrm{L})$ and resistance toclindamycin $(256 \mathrm{mg} / \mathrm{L})$, respectively.

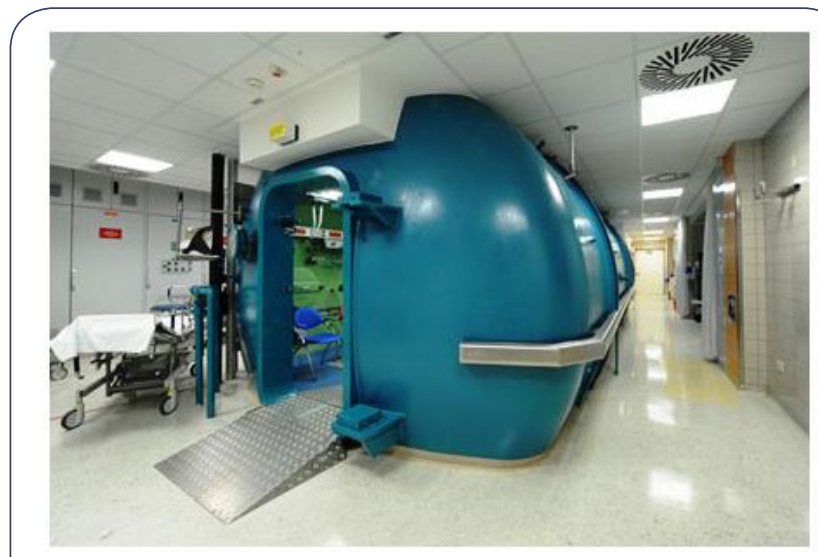

Figure 4. Multiplace-Hyperbaric chamber for emergency HBO.

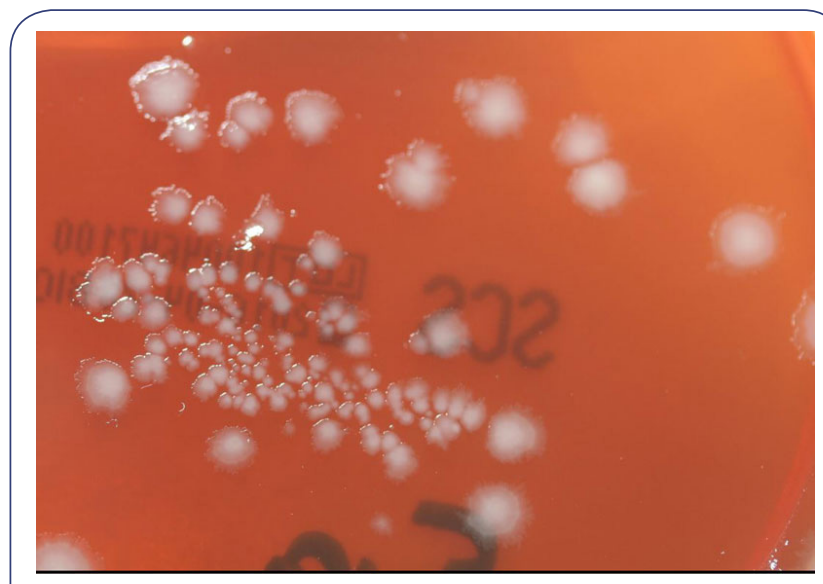

Figure 5. Culture on Schädler agar showed grey-white colonies with crenated edges, no $ß$ - haemolysis was observed.

In the further course a Vacuum-assisted-closure system (VAC System; Kinetic Concepts, Inc; San Antonio, TX) to accelerate proper wound healing was applied after the following microbiologic test results were negative for Clostridia. The abdomen was definitively closed on the third postoperative day. Under combined $\mathrm{HBO}$, antibiotic treatment and intensive care measures the patient recovered uneventfully, and was discharged to the oncological ward on the $14^{\text {th }}$ postoperative day.

\section{Discussion}

Basically Clostridia cause a wide spectrum of severe infections, mainly gas gangrene, necrotizing fasciitis with myonecrosisor even bacteremia. Clostridiumis an anaerobic ubiquitous organism, and can also be found in the human gut [7]. Infectionsmay develop after trauma, after surgeryor even spontaneously. In gas gangrene or necrotizing fasciitis mainly C. perfringens and C. septicum can be found whereas the incidence of C. paraputrificum is extremely rare $[\mathbf{1 - 3 , 8 , 9}]$. Moreover, in most of the cases the extremities are affected. Gas gangrene of the chest, the abdomen or the pelvis is very uncommon and rare. Once these regions of the human body are affected, lethality dramatically rises up to nearly $100 \%$.

This underlying case is hallmarked by a particular combination. On the one hand the very rare subtype $C$. paraputrificium serving as causative agent for spontaneous gas gangrene. On the other hand the uncommon localization affecting the abdominal wall. To our best knowledge this case is the first report of life-threatening abdominal gas gangrene induced by rare $C$. paraputrificium treated successfully with emergency surgery, antibiotics and supportive $\mathrm{HBO}$, respectively.

In the only few reports about infections caused by $C$. paraputrificum, predisposing factors such as HIV, non-cyclic neutropenia, sickle-cell anemia, malignancy, alcohol abuse or diabetes mellitus were present [10-12]. All cases revealed severe sepsis and bacteremia whereas in our patient bacteremia could not be confirmed, because only one pair of blood cultures had been taken, unfortunately after starting antibiotic therapy. These reported infections were predominantly necrotizing processes involving the gut [13] or in one case aspiration pneumonia [14].

With a history of neoadjuvant chemotherapy for breast cancer and diabetes mellitus our patient had two known risk factors for developing gas gangrene. As there was no evidence of intestinal perforation, spontaneous infection in the course of jejunal incarceration was assumed. Supposedly, the organism crossed the wall of the gut following breakdown of the mucosal barrier and entered the soft-tissue overlying the incarcerated hernia.

The striking clinical features were the rapid development of the hemorrhagic, blistering soft-tissue necrosis accompanied by development of considerable septic shock with rapid deterioration of the patient's general condition. These typical clinical signs are pathognomonic for severe soft-tissue infections in particular for life-threatening gas gangrene.

Generally the adequate management of patients with necrotizing soft tissue infections is based on prompt surgical debridement and immediate initiation of empiric intra-venous antibiotic therapy. Broad spectrum antibiotics are advisable until the pathogen is identified [8]. Under these challenging conditions it is of utmost importance to react and proceed im- 
Lindenmann et al. Microbiology Discovery 2016,

mediately even in case of sneaking suspicion of gas gangrene. It is of crucial importance to bear in mind that abdominalgas gangrene may occur, even spontaneously. This is what confronted emergency physicians should think about, so they would be able to identify gas gangrene and can therefore promptly start the adequate interdisciplinary treatment. Any time delay in diagnosis or therapy is associated inevitably with the patient's death particularly in case of gas gangrene affecting the abdominal cavity or the abdominal wall, respectively.

During the elapsed years HBO has been favorably advocated as valuable additive and therefore life-saving treatment option for severe clostridial soft-tissue infections and gas gangrene, respectively [4-7]. At the Clinical Division of Thoracic and Hyperbaric Surgery at the Medical University of Graz, the only center in Austria, HBO for severe necrotizing soft- tissue infections has been successfully applied for many years. The principles of $\mathrm{HBO}$ for the treatment of these challenging life-threatening diseases are described in detail elsewhere [4-7].

\section{Conclusion}

In conclusion this extraordinary case clearly emphasize sthe clinical impact of emergency treatment for life-threatening abdominal gas gangrene. By means of this promptly initiated therapy consisting of aggressive surgery, broad-spectrum antibiotics and consistent HBO, the patient's life could be saved last-minute. It is of crucial importance to initiate these three combined therapeutic steps even in case of sneaking suspicion of gas gangrene in order to obtain the utmost probability for the patient's survival.

\section{Competing interests}

The authors declare that they have no competing interests.

\section{Authors' contributions}

Joerg Lindenmann and Nicole Fink-Neuboeck as both first authors contributed equally to this article. They are responsible for the draft and writing the manuscript, performance of the design and acquisition of the data and repetitive correction of the manuscript, respectively. They provided the two photographs from the emergency room. They have done final approval of the recent version to be considered for publication. Eva Leitner and Andrea Grisold performed the microbiological analysis and edited the microbiological part and paragraphs of this manuscript. Moreover, they provided the two images of the staining and the culture. Peter Kohek performed emergency surgery and all surgical procedures in this case as well as editing the surgical part of this manuscript. Furthermore he provided the intra-operative image. Freyja Maria Smolle-Juettner performed emergency HBO, provided the image of the hyperbaric chamber and helped in the extensive literature search.

\section{Publication history}

Editors: K Madhavan Nampoothiri, CSIR -NIIST, Kerala, India. Rohit Saluja, Charité - Universitätsmedizin, Berlin, Germany. Received: 27 January 2016 Revised: 28 April 2016

Accepted: 30 May 2016 Published: 09 June 2016

\section{References}

1. Stevens DL, Aldape MJ and Bryant AE. Life-threatening clostridial infections. Anaerobe. 2012; 18:254-9. | Article | PubMed

2. Brook I. Microbiology and management of soft tissue and muscle infections. Int J Surg. 2008; 6:328-38. | Article | PubMed

3. Headley AJ. Necrotizing soft tissue infections: a primary care review. Am Fam Physician. 2003; 68:323-8. | Article | PubMed

4. Smolle-Juttner FM, Pinter $\mathrm{H}$, Neuhold KH, Feierl G, Sixl T, Ratzenhofer $B$, Kovac $\mathrm{H}$ and Friehs $\mathrm{G}$. [Hyperbaric surgery and oxygen therapy in clostridial myonecrosis]. Wien Klin Wochenschr. 1995; 107:739-41. | PubMed

5. Shaw JJ, Psoinos C, Emhoff TA, Shah SA and Santry HP. Not just full of hot air: hyperbaric oxygen therapy increases survival in cases of necrotizing soft tissue infections. Surg Infect (LarChmt). 2014; 15:328-35. | Article | PubMed Abstract | PubMed FullText

6. Korhonen K. Hyperbaric oxygen therapy in acute necrotizing infections. With a special reference to the effects on tissue gas tensions. Ann Chir Gynaecol. 2000; 89 Suppl 214:7-36. | PubMed

7. Drasar BS, Goddard P, Heaton S, Peach S and West B. Clostridia isolated from faeces. J Med Microbiol. 1976; 9:63-71. | Article | PubMed

8. Lee HL, Cho SY, Lee DG, Ko Y, Hyun JI, Kim BK, Seo JH, Lee JW and Lee S. A Fatal Spontaneous Gas Gangrene due to Clostridium perfringens during Neutropenia of Allogeneic Stem Cell Transplantation: Case Report and Literature Review. Infect Chemother. 2014; 46:199-203. | Article | PubMed Abstract | PubMed FullText

9. Gurtner T. [Gas gangrene]. Unfallchirurgie. 1983; 9:172-4. | Article | PubMed

10. Brook I and Gluck RS. Clostridium paraputrificum sepsis in sickle cell anemia. South Med J. 1980; 73:1644-5. | PubMed

11. Denamur E, Tumerelle E, Lallement PY, Darchis JP and Veyssier P. [Clostridium paraputrificum fulminant septicemia and gas gangrene disclosing acute promyelocytic leukemia]. LARC Med. 1984; 4:236. I PubMed

12. Shinha T and Hadi C. Clostridium paraputrificum Bacteremia Associated with Colonic Necrosis in a Patient with AIDS. Case Rep Infect Dis. 2015; 2015:312919. | Article | PubMed Abstract | PubMed FullText

13. Shandera WX, Humphrey RL and Stratton LB. Necrotizing enterocolitis associated with Clostridium paraputrificum septicemia. South Med J. 1988; 81:283-4. | PubMed

14. Nachamkin I, DeBlois GE and Dalton HP. Clostridium paraputrificum bacteremia associated with aspiration pneumonia. South Med J. 1982; 75:1023-4. | PubMed

\section{Citation:}

Lindenmann J, Fink-Neuboeck N, Leitner E, Grisold A, Kohek P and Smolle-Juettner F M. Clostridium paraputrificum as rare causative of life-threatening spontaneous necrotizing cellulitis of the abdominal wall. Microbiol Discov. 2016; 4:3.

http://dx.doi.org/10.7243/2052-6180-4-3 